\title{
Linking Organizational Culture and Hospital Information Systems Implementation
}

\author{
Shan Wang ${ }^{1}$, Norm Archer ${ }^{2}$ and Yanli $\mathrm{Pei}^{3}$ \\ 'Department of Management Science, School of Business, Renmin University, 59 Zhong \\ Guan Cun Avenue, Haidian District, Beijing 100872, P.R. China wangs7@gmail.com \\ ${ }^{2}$ DeGroote School of Business, McMaster University, Hamilton L8S 4M4, ON, Canada \\ archer@mcmaster.ca \\ ${ }^{3}$ School of International Business, Beijing Foreign Studies University, Beijing 100089, P.R. \\ China peiyanli@bfsu.edu.cn
}

\begin{abstract}
The impact of organizational culture on the successful implementation of information systems (IS) has been studied by some researchers. However, a close examination of the literature shows that researchers examined different attributes of organizational culture, and for the same culture attributes, researchers donot agree with the actual impact of these attributes on IS implementation. This paper seeks to identify a comprehensive set of relevant organizational attributes that have the potential to impact IS implementation in the healthcare setting. Seven organizational values are investigated through case studies, and most of the attributes are found to affect IT implementation success.
\end{abstract}

Keywords: Enterprise Information Systems (EIS), IS success, Organizational culture

\section{INTRODUCTION}

The use of information technology (IT) offers hospitals tremendous opportunities to attain operational and strategic benefits and positive financial performance[1]. The development and use of Hospital Information System (HIS) in the USA can be traced back to the 1960s, but in China it is a recent initiative [2]. The Golden Health project launched by Ministry of Health of P. R. China in 1995 marked the beginning of HIS development and adoption by hospitals.

Despite the push from the Chinese government, HIS diffusion in Chinese hospitals is limited. A survey showed that in China, $31 \%$ of hospitals implemented HIS, only $7 \%$ of which are the integrated HIS involving most functional departments across the entire hospitals[3]. The slow diffusion of HIS is attributed partly to its complexity. It is an enterprise information system (EIS) and is called hospital ERP. Organizational characteristics of Chinese hospitals also account for the slow diffusion. Chinese hospitals are normally subsidized and controlled by the government. They are less cost cautious and emphasize operational stability in their management. Organization decision making is centralized but communication is informal. These create barriers to the diffusion of HIS. Less cost cautious hospitals have limited incentives to deploy

Please use the following format when citing this chapter:

Wang, S., Archer, N., Pei, Y., 2007, in IFIP International Federation for Information Processing. Volume 254. Research and Practical Issues of Enterprise Information Systems II Volume I. eds. L. Xu. Tjoa A.. Chaudhry S. (Boston: Springer), pp. 617-626. 
HIS, whereas centralized structure may lead to a lack of communication about HIS goals and importance between the top management and employees. Since some of the above potential reasons for the slow HIS diffusion are related to organizational culture, in this research we seek answers to the research question: what attributes of organizational culture affect HIS implementation success?

In the next section, we will provide a brief review of the concepts of organizational culture, and how organizational culture is linked to information system implementation and adoption. Hypotheses are then derived to guide data collection and analysis. We adopted a case study approach to illustrate our hypothesis. This paper contributes to the theories about the role of culture in HIS implementation by investigating a more comprehensive but relevant set of cultural attributes, and to practice by providing key directions for organizational change that would help hospitals to achieve greater HIS success.

\section{LITERATURE REVIEW}

\subsection{Organizational Culture}

There is no universally accepted definition of organizational culture, and some of the most cited culture definitions can be found in $[4,5]$. The characteristics of culture are summarized as the following:

Firstly, culture is normally defined as the shared assumption and value of an organization, which can influence organizational behavior through the formation of norms, rule and practices. It is natural to link culture with organizational performance since by definition, values are assumed to influence or control employee behavior, which is in turn the source of organizational performance[6].

Secondly, culture is hard to observe and articulate. So researchers define them in three levels: value, norm and practice[4]. These three levels of culture are more and more observable and increasingly being able to be articulated.

Thirdly, due to the vague definition of culture and value, it is impossible to exhaust attributes of culture. We could see this from burgeon of organizational culture measurements: to name a few, Competing Value Framework, Organizational Cultural Inventory [7], Hofstede's five cultural dimensions [5], etc.

\subsection{The Role of Culture in IS implementation}

IS Researchers also tried to link organizational culture to the success of IS implementation[8-11]. Leidner and Kayworth[12] provided an excellent overview of the role of culture in IS adoption and implementation. Based on Competing Value Framework, McDermott and Stock [11] examined how different culture type( market, adhocracy, development and hierarchy) are linked to different IT benefits, including satisfaction, operational, organizational, and competitive benefits). 
A detailed examination of previous research results showed that researchers do not agree on how IT effectiveness is affected by culture. For example, Harper and Utley[9]'s and Kanungo[10]'s conclusions contradict with each other. Harper verified that people-oriented culture lead to greater chance of successful IT implementation, whereas Kanungo's work showed that such a culture is not related to the satisfaction of IT implementation. Contradiction in the results can also be found in Ruppel and Harrington[8]'s and McDermott[11]'s work.

These contradictions may be partly due to the use of different measurement of organizational culture and IT effectiveness, but it also implies that more empirical work is needed to verify what organizational culture attributes affect IT implementation effectiveness. Most previous researchers also focus on investigating one culture attribute or instrument, but in our research, we try to include a more comprehensive set of relevant cultural attributes that may affect the HIS implementation, including professional culture and IT culture.

\section{HYPOTHESIS}

Our work is based on Detert et al [13]'s culture framework, which summarized important organizational attributes that are potentially conducive to the implementation of Total Quality Management (TQM). Their culture framework also has overlap with the cultural instruments that are mentioned in the literature review.

In Detert et al.'s framework, seven culture attributes are considered relevant to IS implementation: (1) the basis of truth and rationality, (2) long- or short-term orientation (3) stability vs. change (4) production and people orientation (5) isolation vs. collaboration (6) centralized vs. decentralized control (7) internal vs. external focus. These dimensions are also used by Jones et al. [14] to develop IS implementation culture, and to explain how implementation culture affects the effectiveness of ERP implementation. In this research, we use these seven attributes as general organizational culture attributes, rather than IS implementation culture.

The basis of truth and rationality refers to the extent to which an organization's decision making is based on systematical collection of data and facts, scientific modeling, and statistical analysis, or are experiential and intuitive in nature[13]. If an organization's decision making tends to be scientific and rational, the organization may value the support of information systems. Information systems are not suitable for experiential decision making style since they are poor media that can only accommodate codified knowledge. In China, why the failure rate of ERP system in state owned enterprises(SOEs) is much higher than that of private ventures is attributed to SOEs' experiential decision making style[15].

Hypothesis one: Rational decision making culture leads to greater HIS success.

Long-vs. short-term orientation refers to the time horizon of an organization that "helps determine whether leaders and other organizational members adopt long-term planning and goal setting or focus primarily on the here-and-now"[13]. Long-term horizon culture fits HIS more since HIS is a long term undertaking, with lagged benefits, relatively long implementation time and ongoing improvement of software. 
The hospital management must be patient and farseeing, in order to see a successful HIS implementation. So we propose:

Hypothesis two: A hospital with long-term oriented culture will achieve a higher HIS success than a short term oriented culture.

Stability vs. change culture refers to the extent to which an organization is more stable in nature, or tends more to encourage innovation, personal growth, continuous organizational improvement and changes [16]. The failure of many EISs is frequently attributed to organizational inertia and a lack of organizational change. Since HIS is an innovation for hospitals, it also demands significant organizational innovation capacity and changes in the hospital structure and work process. So we propose:

Hypothesis three: change oriented organizational culture tends to favor the HIS implementation

Production vs. people oriented cultures put different emphases on task and people issues[16]. In a production oriented culture, individuals focuses more on getting the task done efficiently (also called efficiency-oriented culture), whereas in people oriented culture, individuals value social relationships and "being comfortable" in the workplace more, and similar to collectivism culture. The effects of production or people oriented culture on information system implementation are among the most frequently tested cultural attributes. However, their results are quite different. People-oriented culture could be conducive for IS implementation since it encourages user involvement by trusting employees to do a good job and by bringing more ideas to the implementation process[9], whereas efficiency oriented culture could also encourage IS adoption since IS is an impersonal tool that help computers to finish job efficiently. Temporarily, we suppose:

Hypothesis four: people-oriented organizational culture tends to favor the HIS implementation.

Isolation vs. collaboration cultures refers to the extent to which individual work or cooperation among employees is valued in an organization. It is similar to team oriented culture, and is also among the most investigated culture attributes. For an EIS, cross functional communication and collaboration are important. Martinson found that ERP implementation with a cross functional team will achieve greater success. Since HIS is an enterprise level information system, we assume:

Hypothesis five: Collaboration-oriented culture tends to favor HIS implementation.

Centralized and decentralized control refers to the extent to which the decisions are centralized to the top management, and the activities in the organization are tightly controlled. It is normally said that decentralized control is favorable for IS implementation since participating in decision making and more flexibility and autonomy in the use of IS will encourage user involvement and enthusiasm. So we propose:

Hypothesis six: decentralized control tends to favor HIS implementation and use.

Internal vs. external orientation refers to the extent to which organizational improvements are driven by a focus on internal process, improvements or by external, stakeholder desires. External oriented organizations also search actively for new ideas and leadership from outside their traditional bounds. The effect of internal vs. external orientation on HIS success is two sided. Firstly, an internal focus of an organization may adopt an HIS for internal motivation that uses HIS to improve internal process. 
Secondly, researches showed that the use of external consultants is helpful for the adoption of e-business and ERP systems[17]. So we temporally propose that

Hypothesis seven: Internal-oriented culture and the tendency to proactive use of external information tend to favor HIS implementation and use.

\section{METHODOLOGY}

A case study approach was adopted to preliminarily test the above hypotheses. This is because the relationship between culture and HIS implementation must be studied in real organizational setting[18] and few studies have done on this topic, especially in Chinese hospitals.

We studies two hospitals in China: a Chinese medicine hospital in a big city in north china (Hospital I), and a county hospital in middle China (Hospital II). Both are public hospitals that are sponsored and supervised by the local government. For each hospital, we visit them on site, observing how users use information system, finding indicators of the hospital culture, and interviewing staffs either onsite or through telephone. The study last 5 months, including two visits to hospital I, which last one three days for each, and one visits to hospital II, which lasts two days. The interviews are done both during site visits and through telephones, and were guided by a semistructured questionnaire. In each hospital, we interviewed doctors, nurses and the managers who know the HIS adoption and implementation decisions well.

\section{CASE STUDY RESULTS}

\subsection{Case Introduction}

Hospital I is located in the capital city of a province in North China, and is one of the biggest Chinese medicine hospitals in China. This is a comprehensive class-3, grade-A hospital (the highest level of hospital rank in china). It is affiliated with a famous Chinese medicine university, has 744 beds, and 913 staffs including doctors (many of which are also professors), nurses and administrative staff.

This hospital started to implement HIS in 2000, and is claimed to be the earliest hospital that implemented HIS in the city. However in 2005 they changed their system vendor since the old vendor went out of business. The current HIS has the following functions: patient admission and registration, inpatient management, payment processing, order communication between departments, pharmacy management, and material management. During our interview, we found that the users in general were satisfied with the use of this system. However, problems exist. Most users mentioned that the system is too slow, sometimes even slower than manual processing. A few users, especially some young staffs complain the inflexible of system interfaces and functions.

Hospital II is the best local hospital in a county in Middle China. It is a class-2, grade-A hospital, with 325 beds and 674 staffs (including 387 professionals). It is a teaching hospital that provides training to students from several medical schools that 
are close to this county. Hospital II implemented HIS in 2006. Before HIS, the drug department and accounting department have used single PCs to record drug and do bookkeeping. The currently used HIS includes most functions as those implemented in hospital I, except for doctor workstation, information access by hospital management, and some workflow and parameter variations. Overall, the hospital users are satisfied with the use of HIS, although a few nurses complained the extra work they need to do, such as entering the order according to prescriptions. However, due to other benefits of HIS, such as reduced travel between wards, pharmacy, financial department, they seem to be satisfied.

\subsection{Results}

The case study results are arranged by case comparison across each attributes since we believe that comparison and cross case difference will better enable us to illustrate and test the hypothesis. Since the system in Hospital I is much more advanced, so we evaluate the success of HIS in hospital $I$ is greater than that of hospital II. The results are summarized in Table 1, and are explained in detail.

Table 1 Cross Case Comparision

\begin{tabular}{|c|c|c|c|}
\hline Culture attributes & Hospital I & Hospital II & $\begin{array}{l}\text { Hypothesis } \\
\text { Evaluation }\end{array}$ \\
\hline $\begin{array}{l}\text { The basis of truth and } \\
\text { rationality }\end{array}$ & $\begin{array}{l}\text { Medium rational level } \\
\text { due to relatively higher } \\
\text { managerial skill }\end{array}$ & $\begin{array}{l}\text { Less rational due to } \\
\text { limited managerial skill }\end{array}$ & $\bar{Y}$ \\
\hline $\begin{array}{l}\text { Long vs. short } \\
\text { term orientation }\end{array}$ & Long-term orientation & $\begin{array}{cc}\text { Relatively } & \text { short } \\
\text { term orientation } & \end{array}$ & $\mathrm{Y}$ \\
\hline $\begin{array}{cc}\begin{array}{c}\text { Stability } \\
\text { change culture }\end{array} & \text { vs. } \\
\end{array}$ & $\begin{array}{ll}\begin{array}{c}\text { Relatively } \\
\text { oriented }\end{array} & \text { change } \\
\end{array}$ & More Stability & $\mathrm{Y}$ \\
\hline $\begin{array}{l}\text { Production } \begin{array}{r}\text { vs. } \\
\text { people } \\
\text { cultures }\end{array} \text { oriented } \\
\end{array}$ & Production oriented & People oriented & $\mathrm{Y}$ \\
\hline $\begin{array}{c}\text { Isolation vs. } \\
\text { collaboration cultures }\end{array}$ & Collaboration & Collaboration & $\mathbf{N}$ \\
\hline $\begin{array}{c}\text { Centralized vs. } \\
\text { decentralized control }\end{array}$ & Centralized & centralized & $\mathbf{N}$ \\
\hline $\begin{array}{l}\text { Internal vs. } \\
\text { external orientation }\end{array}$ & $\begin{array}{l}\text { Internal orientation } \\
\text { and professional advice } \\
\text { from external software } \\
\text { company }\end{array}$ & External orientation & $\mathbf{Y}$ \\
\hline
\end{tabular}

Note: Y/N refers to "yes"/ "no", which means that the hypothesis corresponding to each cultural attribute is supported/not supported.

The basis of truth and rationality: Senior managers in both hospital claim that data were important to their decision. One manager in Hospital II commented that since they were public hospitals, the tactic and operational decisions were made in the hospital but the strategic decisions about the hospital were made in the local Bureau of Health and were greatly affected by policies of Ministry of Health. At the lower tactic and operational level of decisions, a reliance on data is necessary. The reports from the accounting and statistical department were submitted to the managers every 
week. Managers in hospital I made similar comments. They deemed management control and access to more information that was not available before as one of the biggest benefits and a major incentive to adopt such as a system. However, we noticed that some managers in Hospital I accessed computerized information directly, while most managers in hospital II still relied on printed reports. The limited management knowledge of managers in hospital II also constrained their level of rational decisions. So we think the level of rationality is slightly lower in hospital I. This illustrate that a culture with less rationality of decisions will lead to lower HIS success due to limited incentive and desire for more data.

Long vs. short term orientation: Managers in both hospitals suggested that IT should be a long investment. But for the implementation process, their view and practices were different. The usage of HIS in hospital I lasted for 7 years whereas it has existed for only one year in hospital II. The system in hospital I was customized, which took time to develop and test. So during the implementation, software engineers stayed onsite for half a year. The situation is different in hospital II. The system in hospital II was a off the shelf product that has already been tested in another hospital. The software engineers stayed onsite for only two weeks. However, one common characteristic between them is that, once the system launched, all the employs were required to learn how to use it within one week. This was to guarantee that it caused minimum interference to the daily operation to the hospitals.

From the above argument, we can see that the hospital I has a more long term vision to the IT investment, and leave more time for its implementation. So its system is more success in terms of degree of diffusion.

Stability vs. Change: Hospital I is relatively more changed oriented than hospital II. This can be explaincd mainly by two factors.

First, hospital I is a research oriented hospital that's affiliated to a Chinese medicine university. It has a tradition to encourage innovation. The excellent pool of staffs, including $\mathrm{Ph}$.Ds, numerous master graduates, renders the innovation possible.

Second, hospital II is a local hospital. They are not research oriented but service oriented. Since it is a small city, it's hard to attract talented people, and undergraduates from medical schools are staffs with highest degree in this hospital. The limited technical skill restricts the hospital to be innovative in treatments. Another issue that makes hospital I so conservative is the poor hospital-patient relationship, which is partly attributed to rocketing charges by hospitals in China right now. Patients' distrust puts high pressure on doctors and hospital management, so that they became conservative and more formal in procedures in order to protect themselves. We noticed that poor doctor-patient relationships also affected bigger hospitals such as hospital I, but the effect was much less, since patients still trusted their technical skill. Furthermore, when patients are transferred from local to bigger hospitals in big cities, they are away from local "guanxi" network and is less willing to conflict with doctors.

Due to the above two reasons, we think hospital I is more changed oriented than hospital II. As for the implementation of IT, hospital I made adaptation either to their workflow or to the system, to ensure better performance, whareas in hospital II, only parameters were changed to accommodate hospital specific situation.

Production vs. people oriented cultures: A mixed people and production oriented culture is observed in both hospitals. Hospital service is special since it is 
about people's life. So doctors and nurses are cautious and try best to do jobs well. Sometimes in order to provide the right treatment, they have to sacrifice personal relationships. So in either hospital, the culture is not entirely production or people oriented. However, the following observation made us to evaluate the culture of hospital I more production oriented and that of hospital II more people oriented.

(1) The sense of competition among doctors and nurses are slightly stronger in hospital I, whereas in hospital II, local people are more satisfied with status quo.

(2) In IT implementation, we found that in hospital II, employee tended to help each in learning how to use HIS, whereas in hospital I, people were at a distance, being less willing to seeking help from friends but more from the IT department.

Since HIS in hospital I is more successful than that in hospital $I$, it seems that production oriented culture foster greater success of HIS, for the reason that the efficiency oriented culture drives people to learn how to use HIS efficiently, and to seek services from professionals.

Isolation vs. collaboration cultures: In both hospitals, different functional departments collaborate a lot since hospital service is patient centered. In order to cure a patient, collaboration frequently happens between outpatient and inpatient departments, between financial, drug and clinical departments, between nurses and doctors, and between different clinical departments. So we observed that despite the cross enterprise characteristic of HIS, conflict in departmental interfaces seldom occurred, and even if happened, can be resolved quickly. It seems that collaboration oriented culture are favorable for HIS implementation. But due to the similar level of collaboration, we can not explain the difference of HIS success between two hospitals from the collaboration culture perspective. More evidence is needed to make a solid conclusion.

Centralized and decentralized control: Both hospitals are quite centralized. The decision makings in both hospitals are centralized to the top management. Employees are distant from the top management, and are controlled by hospital procedures and policies. Centralization is favorable to the diffusion of HIS, since employees may perceive the use of HIS as an imperative. As one manager in hospital I said: "sometimes keeping a distance with employee is better for management by maintaining a sense of authorization". Again due to the lack of evidence to justify that the level of centralization in two hospitals' are different, we can not explain the difference of HIS success between them from a centralization cultural perspective. More evidence is needed to make a conclusion.

Internal vs. external orientation: As for non IT internal vs. external orientation, both hospitals have connections with external entities, such as governments, other hospitals and universities. However, due to the local nature of hospital II, the doctors also admitted that their opportunities to study in other hospitals were much less than those in big hospitals such as hospital I. When it comes to HIS implementation, hospital I tends to have a clear goal of greater management control, whereas in hospital II, the launch of HIS is more a result of studying other hospitals. A manager in hospital I commented that by implementing HIS, they could save at least $600,000 \mathrm{RMB}$ each year, just on the loss of charges due to previous poor management 
control. Hospital I seemed to have a clear internal motivation to adopt such a system, and seeked professional advices from software engineers. So the conclusion is that internal-oriented culture and the tendency to proactively use of external advice tend to favor HIS implementation and use.

\section{CONCLUSIONS}

We have investigated the role of nine culture attributes on HIS success, including the basis of truth and rationality, long- or short-term orientation, stability vs. change, production- and people-oriented culture, isolation vs. collaboration, centralized vs. decentralized control, internal or external focus, physician-dominated authoritarian culture, and positive IT value. We found the support for most hypotheses, except for those about isolation vs. collaboration; centralized or decentralized control, and professional culture. The managerial implication of this research is that the hospital leaders can take measures to change the cultural environment that is favorable for HIS implementation.

The future research direction includes investigating each cultural attribute in depth, and measuring them quantitatively. Another research direction is to include more hospitals, especially private hospitals, in the case study. Although we concluded that physician-dominated authoritarian professional culture, which was found affecting HIS adoption in western countries, were less relevant in china, more Chinese professional culture could be explored in the future.

\section{ACKNOWLDGEMENTS}

This research was generally supported by Beijing Foreign Studies University Research funds (Grant IDs are 06040 and 032117)

\section{REFERENCES:}

1. E. Ammenwerth, S. Gräber, T. Bürkle, and C. Iller, Evaluation of Health Information Systems: Challenges and Approaches, in E-Health Systems Diffusion and Use: The Innovation, the User and the UseIT Model, eds. T. Spil and R.W. Schuring (Idea Group Publishing: Hershey, PA, 2005), pp.212-236.

2. X. Zhang, Present status and development of hospital information system, Chinese Medicine Modern Distance Education of China. Volume 9, Number 9, pp.10-, (2005).

3. B. Li, Seven Challenges Faced by Hospital Information System in China, Discovering Value. Volume 2, Number 5, pp.86-, (2004).

4. E.H. Schein, Organizational Culture and Leadership (Jossey Bass Wiley: San Francisco, 1985).

5. G. Hofstede, The Cultural Relativity of Organizational Practices and Theories, Journal of International Business Studies. Volume 14, Number 2, pp.75-89, (1983). 
6. R.E. Quinn and G.M. Spreitzer, The Psychometrics of the Competing Values Culture Instrument and an Analysis of the Impact of Organizational Culture on Quality of Life, Research in Organizational Change and Development. Number 5, pp.115-142, (1991).

7. R. Cooke and J. Szumal, The Reliability and Validity of the Organizational Culture Inventory, Psychological Reports. Volume 72, Number 3, pp.1299-330, (1991).

8. C.P. Ruppel and S.J. Harrington, Sharing Knowledge through Intranets: A Study of Organizational Culture and Intranet Implementation, IEEE Transactions on Professional Communication. Volume 44, Number 1, pp.37-52, (2001).

9. G.R. Harper and D.R. Utley, Organizational culture and successful information technology implementation, Engineering Management Journal. Volume 13, Number 2, pp.11-, (2001).

10. S. Kanungo, An Empirical Study of Organizational Culture and Network-based Computer Use, Computers in Human Behavior. Volume 14, Number 1, pp.79-91, (1998).

11. C.M. McDermott and G.N. Stock, Organizational culture and advanced manufacturing technology implementation, Journal of Operations Management. Volume 17, Number 5, pp.521-533, (1999).

12. D.E. Leidner and T. Kayworth, Review: A Review of Culture in Information Systems Research: Toward a Theory of Information Technology Culture Conflict, MIS Quarterly. Volume 30, Number 2, pp.357-399, (2006).

13. J.R. Detert, R.G. Schroeder, and J.J. Maurie, A Framework for Linking Culture and Improvement Initiatives in Organizations, The Academy of Management Review. Volume 25, Number 4, pp.850-863, (2000).

14. M.C. Jones, M. Cline, and S. Ryan, Exploring knowledge sharing in ERP implementation: an organizational culture framework, Decision Support Systems. Volume 41, Number 2, pp.411-434, (2006).

15. M.G. Martinsons, ERP in China, One package, Two Profiles, Communications of the $A C M$. Volume 47, Number 7, p.65, (2004).

16. R. Cooke and J. Lafferty, Organizational Culture Inventory (OCI) (Human Synergistics: Plymouth, MI, 1987).

17. P. Ifinedo and N. Nahar, ERP systems success: an empirical analysis of how two organizational stakeholder groups prioritize and evaluate relevant measures, Enterprise Information Systems. Volume 1, Number 1, pp.25-48, (2007).

18. R.K. Yin, Case Study Research: Design and Methods (International Educational and Professional Publisher: Thousand Oaks, 1994). 